\title{
The Effect of Depressing Glial Function in Rat Brain In Situ on Ion Homeostasis, Synaptic Transmission, and Neuron Survival
}

\author{
Carlota Largo, ${ }^{1}$ Pedro Cuevas, ${ }^{1}$ George G. Somjen, ${ }^{2}$ Rafael Martín del Río, ${ }^{1}$ and Oscar Herreras ${ }^{1}$ \\ 'Departamento de Investigación, Hospital Ramón y Cajal, 28034 Madrid, Spain, and 2Department of Cell Biology, Duke \\ University Medical Center, Durham, North Carolina 27710
}

The supporting role of glial cells in maintaining neurons and in ion homeostasis has been studied in situ by perfusing the gliotoxin fluorocitrate (FC) through a microdialysis fiber in the CA1 area of urethane-anesthetized rats. Extracellular direct current potential, extracellular potassium concentration $\left(\left[\mathrm{K}^{+}\right]_{\mathrm{o}}\right)$ and amino acid levels, extracellular $\mathrm{pH}\left(\mathrm{pH}_{\mathrm{o}}\right)$, and evoked field activity were studied. Histology verified the swelling of glial cells after $4 \mathrm{hr}$ of FC treatment. Massive neuron damage was evident after $8 \mathrm{hr}$. FC dialysis caused the rapid decrease of glutamine, $\mathrm{pH}_{\circ}$ became progressively more acid, and $\left[\mathrm{K}^{+}\right]_{\circ}$ moderately elevated. Orthodromic transmission was variably blocked within $30 \mathrm{~min}$ to $4 \mathrm{hr}$. After $4 \mathrm{hr}$, spreading depression (SD) waves that originated from the neocortex invaded hippocampal $\mathrm{CA} 1,\left[\mathrm{~K}^{+}\right]_{0}$ increased to higher levels, $\mathrm{pH}_{\mathrm{o}}$ became very acid, and there were steep increases in taurine, glutamate, and GABA levels. Simultaneously, the antidromic population spike (a-PS) became depressed and eventually disappeared. When a shorter dialysis probe that spared cortex was used to sample CA1, no SD was seen, a-PS was not abolished, and ion ho- meostasis was altered less markedly. Repeated SD provoked in hippocampus in the absence of FC caused only mild depression of a-PS. Dialysis of high- $\mathrm{K}^{+}$solution in healthy neocortex or hippocampus caused only slight elevation of $\left[\mathrm{K}^{+}\right]_{0}$ at distances of 200-400 $\mu \mathrm{m}$ from the dialysis membrane. After treatment with $\mathrm{FC}$, similar high- $\mathrm{K}^{+}$dialysis raised $\left[\mathrm{K}^{+}\right]_{0}$ much more. We conclude the following: (1) recurrent SD waves injure neurons if and only if glial function has failed; (2) neurons can regulate $\left[\mathrm{K}^{+}\right]_{0}$, albeit imperfectly; (3) glia is required for the normal fine tuning of $\left[\mathrm{K}^{+}\right]_{0}$ and particularly for the recovery of pathologically elevated $\left[\mathrm{K}^{+}\right]_{0}$; and (4) glia are required for the regulation of $\mathrm{pH}_{\mathrm{o}}$. The similarities between glial poisoning by FC and the reported changes in the penumbra of ischemic infarcts suggest that the extension of neuron loss into the penumbral region might depend on failure of glial protection.

Key words: glia; fluorocitrate; CA1; neuron-glia relations; microdialysis; in vivo; evoked potentials; $\mathrm{pH}_{o} ; \mathrm{K}^{+}$; extracellular space; ion homeostasis; spreading depression; neuron injury
The number of functions attributed to glial cells has grown steadily in recent years (Kettenmann and Ransom, 1995). The multiple interplay among variables makes it difficult to reliably unravel neuron-glia relations. Best documented are the roles of glial cells in maintenance of extracellular homeostasis and metabolic support of neurons. Although it has long been debated whether neurons can survive without their glial satellites, neurons can be cultured on their own (Lodin et al., 1970; Vibulsreth et al., 1987) and do not die in tissue slices after glia poisoning in vitro (Berg-Johnsen et al., 1993; Keyser and Pellmar, 1994). It must be remembered, however, that in experiments in vitro most of the functions typically attributed to glia are taken care of by the experimenter. Literature on brain tissue in vivo is very scarce on this issue (Paulsen et al., 1987).

Whereas neurons are highly susceptible to injury, glial cells are more resistant and are known to survive and proliferate to occupy the spaces left by dead ncurons (cf. Wcigert in Ramón y Cajal, 1992). Particularly, ischemia, anoxia, and hypoglycemia are among the causes of neuronal death that may be survived by glial cells. A wealth of data has accumulated on the mechanisms leading to ischemic neuronal death (for review, see Somjen, 1988;

Received July 7, 1995; revised Nov. 9, 1995; accepted Nov. 17, 1995.

This work was supported by Grant $93 / 661$ from the Fondo de Investigaciones Sanitarias of Spain (FIS). C.L. is the recipient of a fellowship from the FIS

Correspondence should be addressed to Dr. O. Herreras, Departamento de Investigación, Hospital Ramón y Cajal, Ctra. Colmenar km 9, Madrid 28034, Spain. Copyright (C) 1996 Society for Neuroscience $0270-6474 / 96 / 161219-11 \$ 05.00 / 0$
Choi, 1990). Scveral factors apparently contributing to ncuron injury include changes in interstitial levels of chemical agents believed to he controlled by glial cells, such as extracellular $\mathrm{pH}$ $\left(\mathrm{pH}_{\mathrm{o}}\right)$ and potassium $\left(\left[\mathrm{K}^{+}\right]_{\mathrm{o}}\right)$. Astrocyte swelling seems to precede neuronal degeneration in a variety of brain insults even though the astrocytes ultimately survive the neurons (for review, see Kimelberg et al., 1990a). Yet little is known of the participation of these cells in the events leading to neuronal demise.

Our purpose was to investigate whether selective injury to glial cells could adversely affect neuronal function and survival. Therc is considerable evidence that the hypoxic depolarization resembling spreading depression (SD) (I eão, 1944) is a major factor in the selective vulnerability of neurons (Balestrino et al., 1989; Somjen et al., 1990) and that waves of SD emanating from the border zone of a necrotic focus are responsible for extending damage into the penumbral region (Nedergaard and Astrup, 1986; Hossmann, 1994). For these reasons we have studied the occurrence of SD as well as synaptically transmitted and antidromically conducted responses in rat brain treated with the selective glial poison, fluorocitrate (FC) (Paulsen et al., 1987). This compound has heen characterized as a "suicide" substrate for the enzyme aconitase, which is selectively taken up by glial cells (Clarke et al., 1970), rapidly halting their tricarboxylic acid (TCA) cycle. By measuring electrophysiological and biochemical variables and histology, we found a close analogy between selective glia poisoning and the evolution of the penumbra of a brain infarct. The experiments also have led to new insights concerning 
the participation of glial cells and neurons in interstitial ion homeostasis in cerebral tissue in situ.

Some of these results have been presented in abstract form (Herreras et al., 1995; Largo et al., 1995).

\section{MATERIALS AND METHODS}

Preparation and recording. Experiments were performed in the dorsal CA1 region of 58 urethane anesthetized $(1.2 \mathrm{gm} / \mathrm{kg}$, i.p.) female SpragueDawley rats weighing $200-250 \mathrm{gm}$. Body temperature was maintained at $37 \pm 0.1^{\circ} \mathrm{C}$ with a heating blanket. Surgery and stereotaxic procedures were performed as described previously in detail (Herreras, 1990). A concentric bipolar stimulating electrode was placed in the alveus for antidromic activation (anterior -5.5 , lateral 2.6, ventral -1.8 ) or in the ipsilateral CA3 field for orthodromic activation of the CA1 field (from bregma, midline, and cortical surface, anterior -3.2 , lateral 2.6 , ventral $-3.3)$. These points were approached at a $30^{\circ}$ angle in the sagittal plane, and depth was subsequently adjusted after placement of the recording electrodes to find the point of lowest threshold for the desired evoked response. Recording electrodes were glass micropipettes filled with 150 $\mathrm{mm} \mathrm{NaCl}(5-10 \mathrm{M} \Omega)$. One to three pipettes were usually placed at the cell body layer of CA1 field and/or in the stratum (st.) radiatum, guided by the typical evoked potentials. One of the pipettes was always positioned within $300-500 \mu \mathrm{m}$ of the dialysis surface.

$\mathrm{The} \mathrm{Ag} / \mathrm{AgCl}$ wires of recording micropipettes were connected to direct current (DC)-coupled field effect transistor input stages. A subcutaneous $\mathrm{Ag} / \mathrm{AgCl}$ wire electrode located under the neck skin of the animal served as reference. After amplification, DC signals were recorded on VCR and processed by AXOTAPE (Axon Instruments, Foster City, CA) computer program acquired either at $5-20 \mathrm{~Hz}$ or at $5-10 \mathrm{KHz}$ sample rate and then further analyzed by the AXUM program (Trimetrix, Seattle, WA).

Double-barreled ion-selective microelectrodes were manufactured as described clsewhere (Somjen, 1981). The Fluka ion cxchangers 60031 and 95297 (Fluka, Buchs, Switzerland) were used as liquid membranes for $\mathrm{K}^{+}$ and $\mathrm{H}^{+}$, respectively, and the World Precision Instruments cocktail IE-190 (World Precision Instruments, Sarasota, FL) was used for $\mathrm{K}^{+}$or tetramethyl ammonium chloride (TMA-Cl). The liquid membrane was $\sim 800 \mu \mathrm{m}$ long. Electrodes were calibrated before and after each experiment and results were rejected on rare occasion when the two differed by $>10 \%$. The reference barrel was used for the recording of evoked potentials and DC voltages. The voltages recorded by the ion-selective electrodes were transformed to a linear millimolar scale with the AXUM program, taking into account the calibrated sensitivity of each electrode. Given the long duration of the experiments, $\mathrm{K}^{+}$electrodes of exceptional stability were needed to accurately describe some of the minor shifts we are reporting. A complicating factor was that basal $\left[\mathrm{K}^{+}\right]_{\mathrm{o}}$ in the CA1 rcgion could not always be reliably measured from a calibrated solution bathing the cortex because of spurious sources for DC potential as the electrode was inserted into the tissue. In these cases it was assumed that the resting $\left[\mathrm{K}^{+}\right]_{0}$ was $3.4 \mathrm{~mm}$.

Microdialysis. Microdialysis was used to deliver the $\mathrm{FC}$ into the tissue and to measure amino acid levels in the interstitial fluid by collection of dialysate samples. Dialysis probes were manufactured as described previously (Herreras et al., 1989, 1994). The active dialysis membrane (outer diameter, $220 \mu \mathrm{m}$ ) for one group of experiments was a cylinder $1 \mathrm{~mm}$ long and, for another group of experiments, shortened to $600 \mu \mathrm{m}$. This was done after we detected that the length of the probe affects the outcome (see Results); we refer to them as long and short probes, respectively.

Before inserting the probe in the brain a micropipette electrode was introduced to find an appropriate location, guided by recording the crokcd potcntial. The probe was lowered thereafter to the same position so that most or the entire dorsoventral extension of the CA1 region was exposed to dialysis by the short or the long probes, respectively. The location was (from bregma): anterior -4 to -5.5 , lateral $2.6-3$. The choice of laterocaudal or rostromedial position depended on whether the stimulating electrode was aimed at orthodromic or antidromic activation and whether we needed to allow room for multiple recording electrodes. Insertion of the dialysis probe invariably provoked a single SD wave, recorded by a nearby micropipette.

A control artificial CSF (ACSF) of the following composition was initially perfused (in mmol/l): $122 \mathrm{NaCl}, 3 \mathrm{KCl}, 0.4 \mathrm{KH}_{2} \mathrm{PO}_{4}, 1.2 \mathrm{CaCl}_{2}$, $1.2 \mathrm{MgSO}_{4}, 25 \mathrm{NaHCO}_{3}$. A Gilson peristaltic pump (Gilson Medical, Villiers Le Bel, France) was used at a constant rate of $2 \mu \mathrm{l} / \mathrm{min}$. A $90 \mathrm{~min}$ rest period was allowed after the probe implantation before the experi- ment began. After three 10 min control samples were collected, a $5 \mathrm{~min}$ period of high- $\mathrm{K}^{+} \mathrm{ACSF}(100 \mathrm{mOsm} / \mathrm{l} \mathrm{KCl}$ substituting equivalent amount of $\mathrm{NaCl}$ ) was perfused to elicit a control SD waveform. Thirty minutes later, 1 mim FC was perfused for 8 hr in most experiments, or for shorter periods. In some experiments, $10 \mathrm{~mm}$ glucose was added anticipating increased demand of glucose as a glutamate precursor (Ward et al., 1983). Results have been pooled because no differences were found whether glucose was present or not. At the end of each hour, a $10 \mathrm{~min}$ sample $(20 \mu \mathrm{l})$ was collected and its amino acid content was analyzed by HPLC as described previously (Lerma et al., 1986). Samples collected when an SD wave developed were discarded, and the next 10 min were used for collection. The actual concentrations of amino acids calculated for the current experiments may have some error because of the changing properties of tissue. However, because the apparent diffusion constant used in our estimating method (Lerma et al., 1986) is dominated by the interaction of each amino acid with the dialysis membrane itself, which is constant, changes in tissue properties may introduce a significant but only modest error.

FC was prepared from its barium salt after precipitation of the barium with sodium sulfate as described by Paulsen et al. (1987), and $\mathrm{pH}$ was adjusted to 7.2-7.3. The actual concentration of drugs at specific distances from the dialysis fiber cannot be determined. From our experience, the concentration of water-soluble compounds that produces a definite electrophysiogical effect at a distance of $300-500 \mu \mathrm{m}$ away from the fiber must be $\sim 10$ times higher in the perfusate than that required to exert the same effect as when administered in the bathing fluid of in vitro preparations (Herreras et al., 1989; Herreras and Somjen, 1993a,b). For the current experiments we routinely used $1 \mathrm{~mm} \mathrm{FC}$, which is an $\sim 10$-fold higher concentration than used to inhibit astrocyte metabolism in vitro (Berg-Johnsen et al., 1993). However, slight variations on the FC concentration may have been caused by barium precipitation.

Pressure ejection of high $-K^{+}$solution. SD waves were sometimes elicited by pressure ejection of $25-50 \mathrm{nl}$ of $1 \mathrm{M} \mathrm{KCl}$ from a glass micropipette (2-5 $\mu \mathrm{m}$ at the tip) located $\sim 100 \mu \mathrm{m}$ below the pyramidal cell layer. This position showed the lowest threshold to provoke SD (Herreras and Somjen, 1993b). The same pipette also was used for electrical recording, enabling the monitoring of evoked potentials during insertion for the accurate placement of the pipette and, subsequently, the registration of the voltage at the site of SD initiation. When no pressure was applied, a stable DC baseline and normal evoked potentials recorded from the high- $\mathrm{K}^{+}$pipette indicated that leakage of $\mathrm{K}^{+}$was negligible or readily buffered by surrounding cells and/or by diffusion.

$\mathrm{K}^{+}$diffusion experiments. Diffusion of $\mathrm{K}^{+}$ions in the interstitial space was studied by dialyzing 30-125 mM KCl-modified Ringer's solution for short periods and measuring $\left[\mathrm{K}^{+} l_{n}\right.$ at known distances from the surface of the dialysis membrane by a $\mathrm{K}^{+}$-selective electrode. Control measurements were performed in $0.4 \%$ agar embedded in $147 \mathrm{mM} \mathrm{NaCl}$ with 3 $\mathrm{mM} \mathrm{KCl}$, as well as in the superficial layers of the somatosensory cortex and in the CA1 region in situ. In the CA1 region, free diffusion was assessed by dialysis of $\mathrm{TMA}^{+}$in three control experiments. To achieve a basal stcady signal of $\mathrm{TMA}^{+}, 1 \mathrm{mM}$ of this substance was pcrfuscd continuously through the dialysis probe before higher concentrations were administered. The actual $\mathrm{TMA}^{+}$concentration in the extracellular space (ES) is not known, and only relative changes can be obtained. Given the length of the experiments (up to $10 \mathrm{hr}$ ), it was difficult to assess the exact $\left[\mathrm{K}^{+}\right]_{0}$ before perfusion of high $\mathrm{K}^{+}$because of electrode drift and small changes in electrode sensitivity. Recalibration of electrodes during the experiment was not advisable for several technical reasons and, therefore, the absolute values may not be accurate. We have used 6 animals (of 8$)$ in which $30(n=1), 50(n=3), 100(n=1)$, or $125(n=$ 1) $\mathrm{mM} \mathrm{KCl}$ was perfused through the long probe during FC treatment. All ACSF constituents and the FC used in this study were obtained from Sigma (St. Louis, MO).

Histology. Four or eight hours after FC perfusion began, selected animals $(n=6)$ were perfused through the abclominal aorta with $150 \mathrm{ml}$ of PBS containing heparin $(0.1 \%)$ followed by a mixture of $p$-formaldehyde $(1 \%)$ and glutaraldehyde $(3 \%)$. The brains were removed and kept for $2 \mathrm{~d}$ in the same fixative at $4^{\circ} \mathrm{C}$. The tissue was sampled under the stereomicroscope in $1 \mathrm{~mm}$ cubes around the dialysis fiber and processed further for microscopy using Epon 812 (Serva, Heidelberg, Germany) or paraffin as the embedding medium. Semithin sections $(0.5-1$ $\mu \mathrm{m}$; Epon) stained with toluidine blue or thick sections ( $6 \mu \mathrm{m}$, paraffin) stained with cresyl violet were examined with the light microscope.

Technical considerations. Because not all variables could be recorded in any one preparation, we varied the combinations in successive experi- 
ments. This enabled us to correlate all combinations in the same brain in at least part of the trials over the course of the 58 experiments that were performed. All data and plots are expressed as the mean \pm SEM.

\section{RESULTS}

\section{Loss of neuronal function after glia poisoning}

Orthodromic transmission was variably affected by FC perfusion. In 6 of 10 experiments, the orthodromic population spike (u-PS) was depressed or abolished within $40-120 \mathrm{~min}$, but in the others it did not start declining until 4-5 hr, except transiently during the passage of SD waves and the on-off cycles during recurrent seizure activity (see below). Occasionally $(n=2)$, an initial period of hypertransmission developed before the gradual extinction. In two additional animals the extracellular field EPSP (fEPSP) was recorded from the st. radiatum $350 \mu \mathrm{m}$ below the cell body layer. The fEPSP was almost completely suppressed within $2 \mathrm{hr}$ of FC administration.

Epileptiform activity developed in some experiments (18 of 58) that slowly and variably unfolded from isolated interictal spikes to ictal-type electrographic seizures lasting 20-30 sec and repeating at 1-2 min intervals. When orthodromic activation was used, multiple o-PSs appeared in response to single stimuli before abolition. In three additional experiments, diluting the FC solution $(0.5 \mathrm{~mm})$ prevented the development of seizures, but we have not explored this dose-effect relationship further.

Because of the variable behavior of orthodromic transmission, antidromic activation was considered a better index of neuronal electrogenic function and survival. To our surprise, the evolution of the antidromic population spike (a-PS) depended on the length of the dialysis probe. Initially, all experiments were performed using the long probe (see Materials and Methods), and the a-PS began to decline at $\sim 3-5 \mathrm{hr}$ of FC perfusion (Fig. 1). The decline of the a PS was gradual, and it was more pronounced at sites closer to the dialysis probe (Fig. $1 A$ ). Once it began, the depression of the a-PS was complete in 1-2 hr. In Figure $2 A$, the mean amplitude of the a-PS recorded within 300-500 $\mu \mathrm{m}$ from the long dialysis probe is plotted (filled circles; $n=7$ ).

The depression of the a-PS began at the same time as the appearance of the first SD waves, which usually repeated at regular intervals of $\sim 15 \mathrm{~min}$. The amplitude of the negative potential shifts $\left(\Delta V_{\mathrm{o}}\right)$ gradually decreased with time as well (see Figs. 6, 8). The timing of SD occurrence in 12 experiments using the long probe is shown in the raster display of Figure $4 A$. In those experiments in which recurrent seizures developed instead of SD waves, the antidromic stimuli triggered multiple spikes and the depression of the a-PS began earlier, but full extinction occurred at the usual time. These experiments were not included in Figure $2 A$.

Using multiple recordings and a moving pipette, we detected that $\mathrm{SD}$ waves did not originate in the hippocampal formation but in the neocortex dorsal to it. The long dialysis probe extended into this region for $-200-300 \mu \mathrm{m}$. We also noticed that a-PSs were less depressed when fewer SD waves invaded the CA1 region. We then proceeded to test the role of SD waves interacting with $\mathrm{FC}$ in causing neuron injury.

Using the shortened dialysis membrane to limit delivery of $\mathrm{FC}$ to the CA1 region in five experiments, after $8 \mathrm{hr}$ of $\mathrm{FC}$ perfusion in only one case did a single SD wave arise. In two other cases seizure activity was seen. During FC administration by the short probe the a-PS was only moderately depressed (Fig. $2 A$, open circles), mainly in the one case in which an episode of SD occurred. Figure $1 B$ illustrates the a-PS in one trial with the short
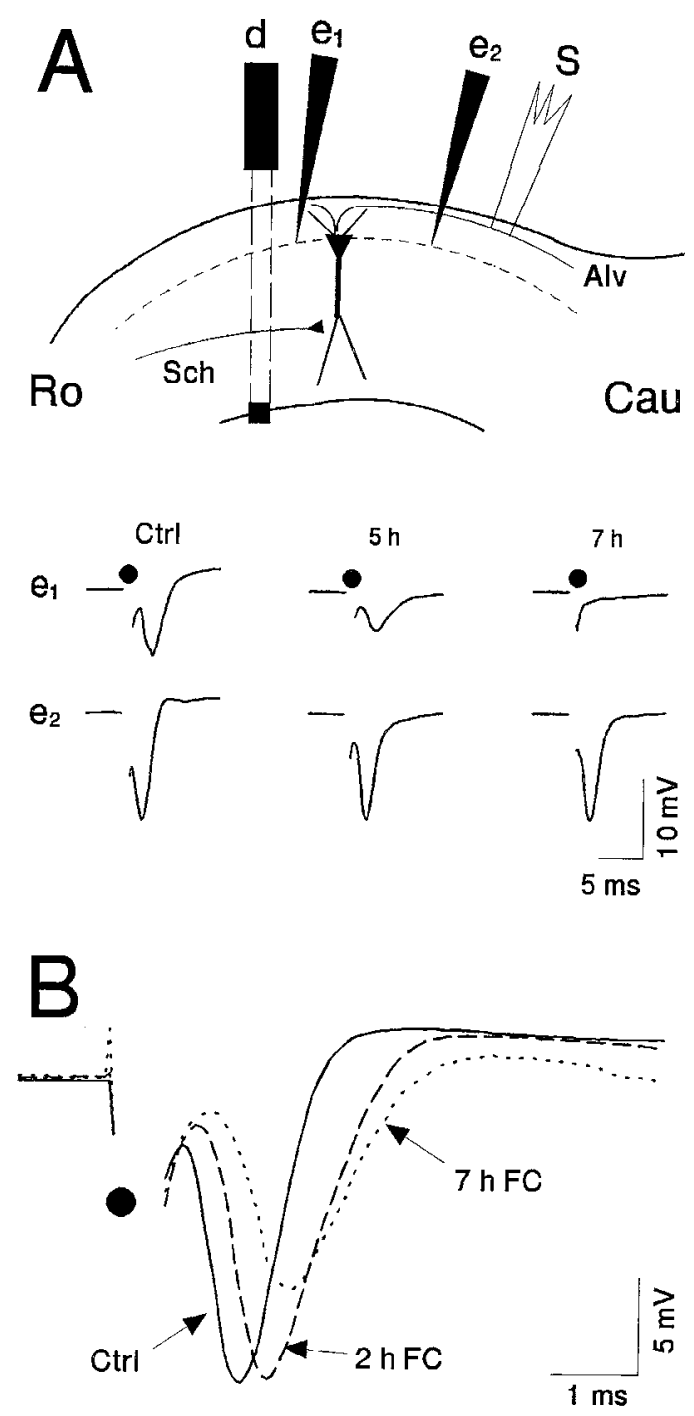

Figure 1. Evolution of the a-PS during $1 \mathrm{~mm}$ FC dialysis. $A$, The top scheme shows the electrode arrangement. Recording electrodes $e 1$ and $e 2$ are located in the st. pyramidalc (dashed line). a-PSs arc cvoked by a stimulating electrode $S$ in the alvear tract $(A l v) ; d$ indicates the dialysis fiber, rostral to the electrodes; Ro, rostral; Cau, caudal; Sch, Schaffer collaterals. The bottom scheme shows the typical evoked a-PSs before $(C t r l)$ and at 5 and $7 \mathrm{hr}$ of $\mathrm{FC}$ treatment $(5 h, 7 h)$, near $(e l)$ and far from (e2) a long dialysis probe in an experiment in which multiple SD waves developed. a-PS blockade is maximal the closer to the source of FC. $B$, Superposition of a-PSs recorded close to a short dialysis probe in another experiment in which no SD waves occurred. There was only partial a-PS blockade. Black dots in $A$ and $B$ mark the artifact of the stimuli.

probe, showing some depression and broadening a-PS, and a delay of its onset. This indicates slowing of axonal conduction and some depression of electrogenic properties without the complete failure observed previously. To test whether a decrease in the amount of FC released by the short probe was responsible for the absence of SD waves, we doubled FC concentration in two additional experiments, and still no SD appcarcd.

In three other experiments we tested whether advancing the appearance of SD waves would also hasten the depression of the a-PS. To this end FC was administered through a long probe, and after $2 \mathrm{hr}$ of FC dialysis $15 \mathrm{SD}$ waves were provoked by microinjection of $\mathrm{K}^{+}$in st. radiatum (see Materials and Methods) at intervals of 7-8 min. The amplitude of the a-PS was measured 

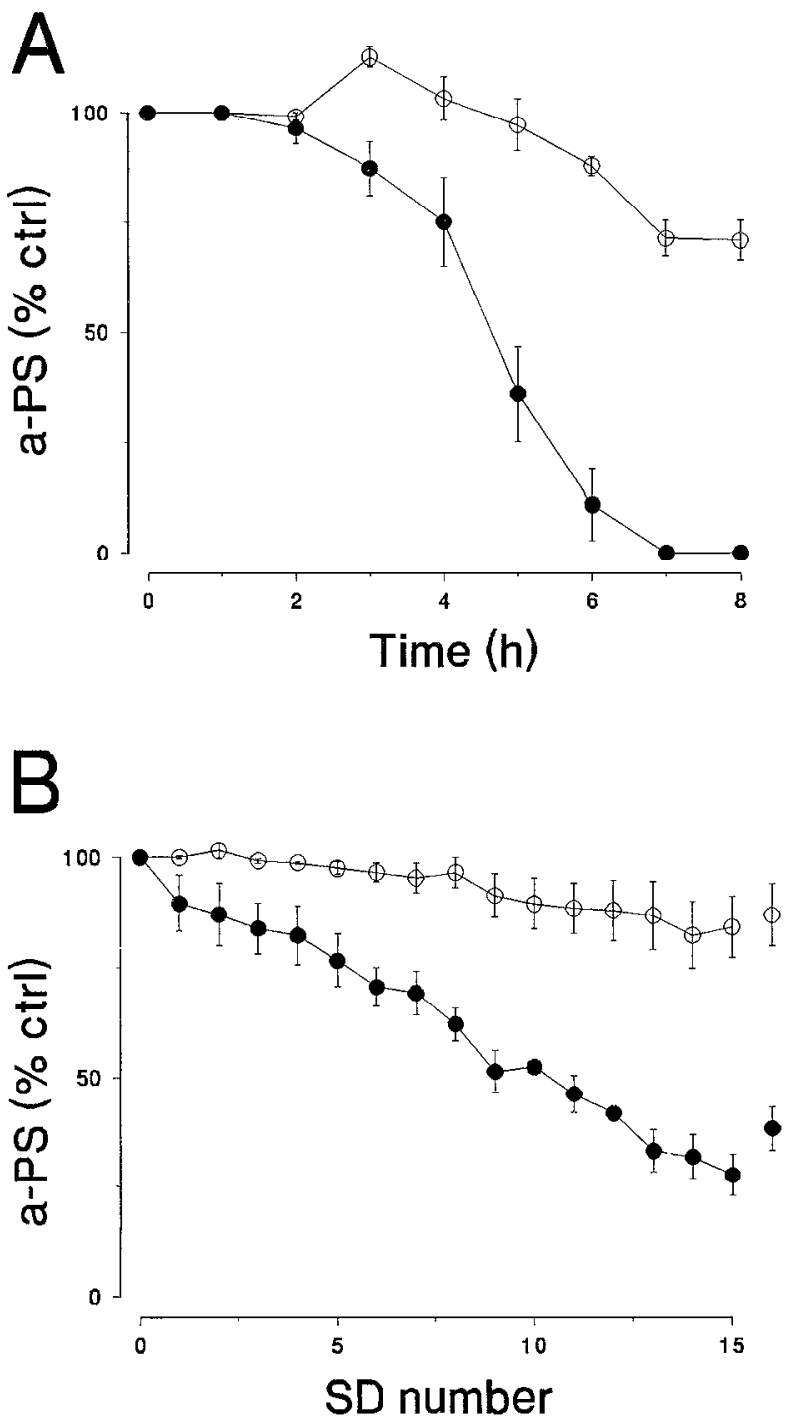

Figure 2. Recurrent SD waves cause loss of neuronal function after glia poisoning. $A$, Mean \pm SEM a-PS amplitude during FC perfusion. Filled circles: trials in which SD waves developed ( $n=7$, long probe). Open circles: no SD recorded ( $n=3$, short probe). $B$, Evolution of the a-PS after each of $15 \mathrm{SD}$ waves provoked by $\mathrm{K}^{+}$microejection at 7-8 min interval in the absence (open circles; $n=3$ ) and after 2 hr of FC perfused through a long dialysis fiber (filled circles; $n=3$ ). a-PS amplitude was measured just before the next SD wave was provoked. The right-most point shows the a-PS 1 hr after the last SD wave.

immediately before injection of $\mathrm{K}^{+}$to allow for recovery from the preceding SD. Figure $2 B$ (filled circles) illustrates the profound depression of the a-PS by this treatment. In three additional experiments SD was similarly provoked without FC dialysis. As in a previous study (Herreras and Somjen, 1993c), repeated SD waves by themselves had no significant effect on the a-PS (Fig. $2 B$, open circles).

These results suggested that repeated SD waves damage neurons if and only if glial cells have been injured previously. To confirm this supposition, it was necessary to check cell integrity by histology.

\section{Histology}

We examined by light microscopy the hippocampal formation in three rat brains that were treated by $\mathrm{FC}^{-}$dialysis by the long probe for $4 \mathrm{hr}$. In these hippocampi, glial cells were obviously patholog- ical. Figure $3 A$ shows a detail from the st. radiatum where astrocyte cell bodies ( $a$ ) and perivascular endfeet (star) appear white, empty, and swollen, displaying an edematous image. This abnormal appearance was observed within at least $500 \mu \mathrm{m}$ from the dialysis probe and throughout the full dorsoventral extension of the dorsal CAI. Neurons ( $n$ ) had a normal appearance.

In three additional brains, after $8 \mathrm{hr}$ of $\mathrm{FC}$ treatment similar changes were observed in glial cells, now always extending throughout the entire dorsal CA1 region. In one of these three brains that had undergone three SD waves and only incomplete blockade of a-PS, a few neurons showed dark nuclei and cytoplasm edema. Strikingly, those few injured neurons were clustered in groups of two to six cells (see example in Fig. 3B). In the other two brains that had experienced more than $10 \mathrm{SD}$ waves, a large extension of the CA1 pyramidal layer had an edematous appearance, and most pyramidal cells had dark and shrunken nuclei (Fig. $3 C$ ). Figure $3 D$ shows a control section after 8 hr of perfusion with ACSF.

\section{Evolution of extracellular amino acid levels}

Figure $4 B$ (filled symbols) shows the pattern of extracellular amino acids during $\mathrm{FC}$ perfusion through a long probe, i.e., when neuronal function eventually becomes impaired. The earliest changes were a severe drop in glutamine levels noticeable already after the first hour and decreasing to $10 \%$ of control; an abrupt increase in alanine level also after $1 \mathrm{hr}$ and rising to $400 \%$; and a drop in aspartate, which recovered partially. These levels were reached within the first $2 \mathrm{hr}$ of FC perfusion. All the other amino acids increased in the ES to varying degrees. The rise of glutamate, taurine, glycine, and GABA was particularly steep. The onset of the steep rise of these four amino acids varied from 4 to $6 \mathrm{hr}$ of $\mathrm{FC}$ perfusion in different trials, always coinciding with the eruption of SD waves and the decline of the a-PS [compare Figs. $2 A$ (filled circles) and $4 A, B$ ).

To assess whether these late amino acid levels were caused by a massive cell breakdown during FC perfusion, a postmortem sample was collected by dialysis from six animals 10 min after killing, and its amino acid content was analyzed. All amino acids except glutamine and arginine were higher than the last in vivo sample. Specifically, in percentage of control, aspartate was 317.14 \pm 88.9 postmortem compared with $89.1 \pm 14.4$ at the end of $8 \mathrm{hr}$ of FC administration; glutamate rose to $2261.7 \pm 410.6$ compared with $750.2 \pm 179.4$. The high variability of the postmortem samples indicated by the large SEM was most likely caused by the varying timing and extent of neuronal breakdown before killing.

In three experiments in which the short probe was used, the early changes in amino acid levels were similar, but the steep rise of glutamate, taurine, glycine, and GABA after the fourth hour, which was always seen with the long probe, did not occur (Fig. $4 B$, open symbols). This reinforced the correlation among SD occurrence, neuronal damage, and the release of these amino acids to the interstitial space.

\section{Changes in $\left[\mathrm{K}^{+}\right]_{\mathrm{o}}$ during glia poisoning}

In 10 preparations $\left[\mathrm{K}^{+}\right]_{0}$ was monitored continuously during the $8 \mathrm{hr}$ of FC perfusion (long probe, $n=8$; short probe, $n=2$ ). In six experiments with the long probe, $\left[\mathrm{K}^{+}\right]_{0}$ increased slightly within the first $1-2 \mathrm{hr}$ of $\mathrm{FC}$ dialysis (increase of $<2 \mathrm{~mm}$; see dotted $\mathrm{K}^{+}$baseline in Fig. 5) and then remained stationary until the eruption of $\mathrm{SD}$ waves. In two other animals, $\left[\mathrm{K}^{+}\right]_{\mathrm{o}}$ first decreased slightly before increasing. When the short probe was used $(n=2)$ so that $\mathrm{SD}$ was avoided, $\left[\mathrm{K}^{\dagger}\right]_{0}$ remained at a constant, moderately elevated level for $8 \mathrm{hr}$ (data not shown). 

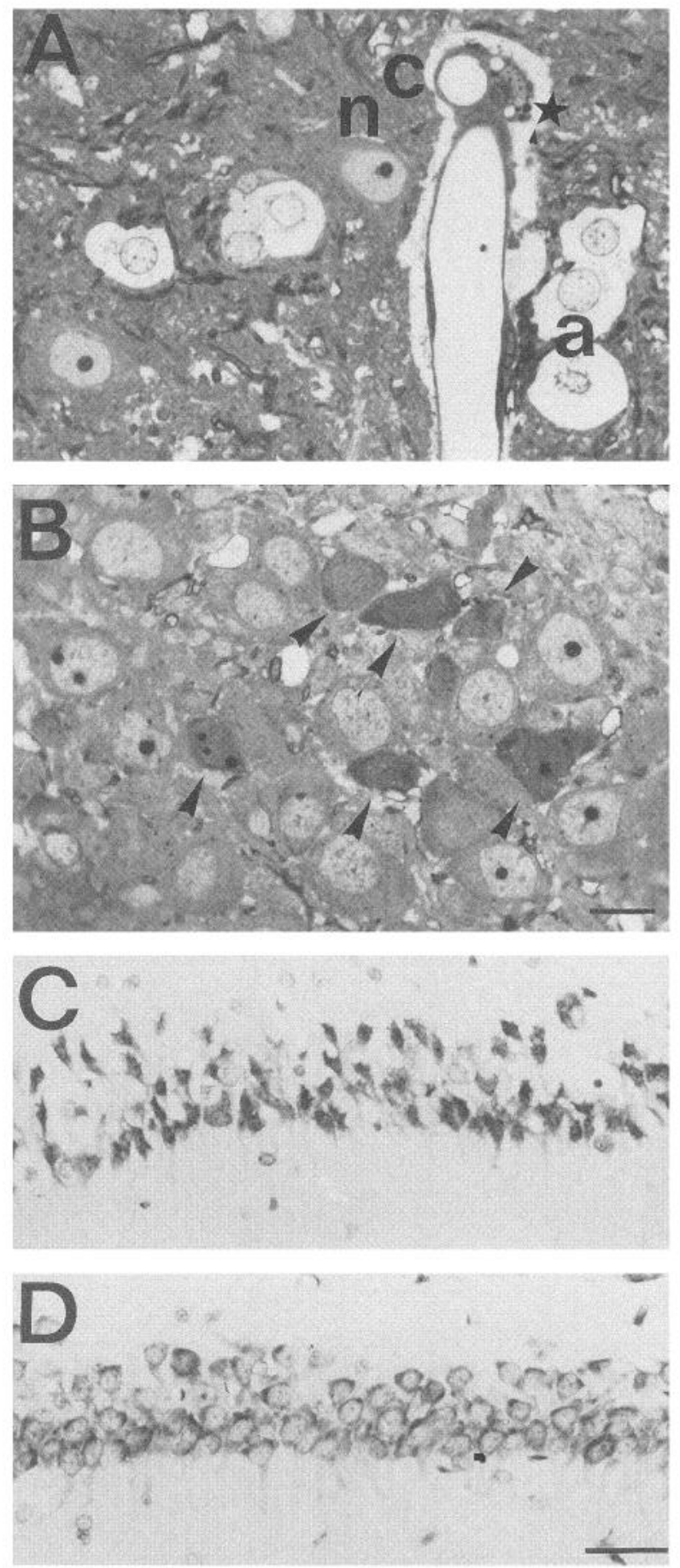

Figure 3. Histological changes after administration of FC through a long dialysis probe. $A$, Detail of a section at the st. radiatum after $4 \mathrm{hr}$ of FC showing the white and swollen and empty appearance of astrocyte somata (a) and the perivascular endfeet (star) surrounding a capillary $(c)$. The tubular white image corresponds to an arteriole from which the capillary branches out. Two neuronal somata $(n)$ also can be observed with normal appearance and a patent nucleolus. $B$, Detail of the CA1 cell body layer from an animal that had partial blockade of the a-PS after $8 \mathrm{hr}$ of FC perfusion. A group of damaged neurons showing dark cell bodies (arrowheads) appeared intermingled with others of normal appearance. $C$, Detail of the CA1 cell body layer from another animal perfused for $8 \mathrm{hr}$ with FC. This animal developed 12 SD waves and had complete blockade of the a-PS. Note the dark and shrunken nuclei. $D$, Normal appearance of CA1 st. pyramidale in a control animal perfused for $8 \mathrm{hr}$ with ACSF. $A$ and $B$ are stained with toluidine blue, and $C$ and $D$ are stained with cresyl violet. Calibration bars: $A, B, 10 \mu \mathrm{m} ; C, D, 50 \mu \mathrm{m}$.
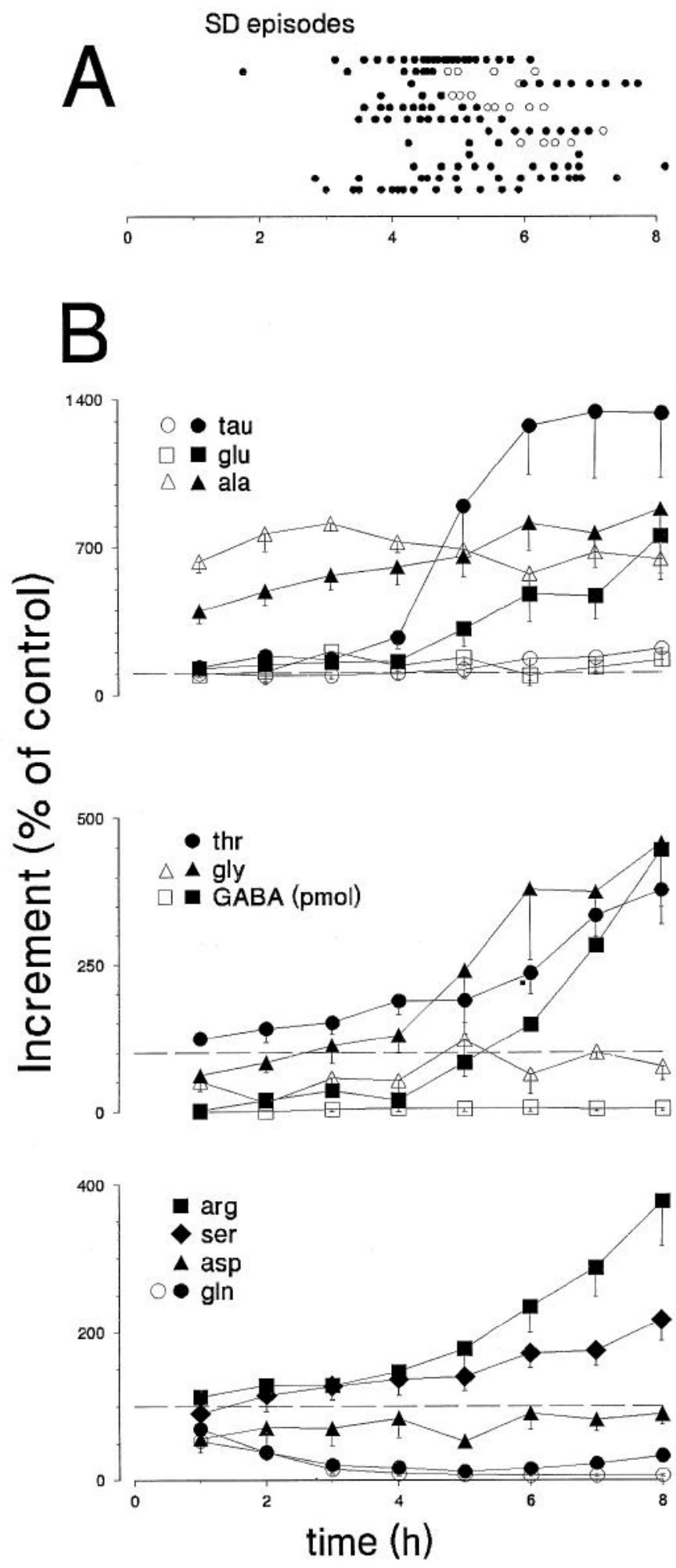

Figure 4. Variations of amino acid concentrations in dialysate during FC administration. All except GABA are in percentage of pre-FC control; GABA levels are shown in pmol because control concentration was too low for quantitative determination. $A$, Raster display showing the timing of spontaneous SD waves in 12 experiments using the long dialysis fiber. Open circles denote cortical SD waves that failed to invade the CA1 region. $B$, Evolution of amino acid levels. Note different ordinate scales of the three graphs; the broken horizontal lines indicate pretreatment control level $(100 \%)$. Filled symbols correspond to experiments in which multiple SD waves developed (long probe), and open symbols correspond to experiments in which they did not (short probe). 


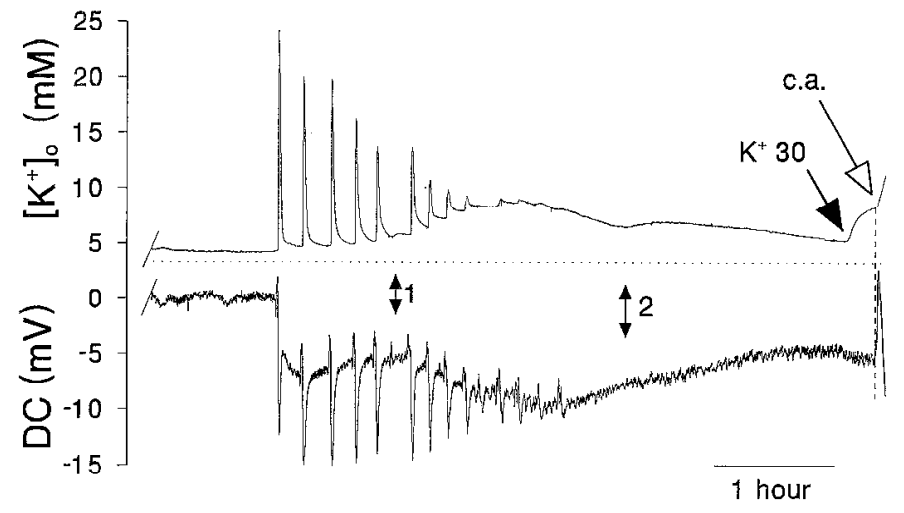

Figure 5. Interstitial $\mathrm{K}^{+}$during repcated spontancous $\mathrm{SD}$ waves (long probe experiment) in st. pyramidale. The traces begin at $150 \mathrm{~min}$ of $\mathrm{FC}$ perfusion, when $\mathrm{K}^{+}$has already slightly increased above initial baseline (dotted line). Double-headed arrow labeled 1 indicates a cortical SD wave that failed to invade the CA1. At double-headed arrow 2, the $\mathrm{K}^{+}$electrode was advanced by $100 \mu \mathrm{m}$ into the st. radiatum. At the black-tipped arrow, $30 \mathrm{~mm} \mathrm{KCl}$ was perfused through the dialysis fiber. Vertical dashed line marks the timing of cardiac arrest (c.a., open-tipped arrow).

During the first $\mathrm{SD}$ waves, $\mathrm{K}^{+}$transients reached typically up to $30-45 \mathrm{~mm}$. Later, the amplitude of $\Delta\left[\mathrm{K}^{+}\right]_{\mathrm{o}}$ transients decreased, as did that of the $\Delta V_{\text {o }}$ waves (Fig. 5). Between SD waves, $\left[\mathrm{K}^{+}\right]_{0}$ did not recover completely, causing a gradual accumulation of $\left[\mathrm{K}^{+}\right]_{\mathrm{o}}$ and the build-up of steady negative potential (Fig. 5). Comparing data from different experiments with ion-selective electrodes at varying distances from the dialysis probe, it appears that the steadily elevated level of $\left[\mathrm{K}^{+}\right]_{0}$ was highest at $200-400$ $\mu \mathrm{m}$ from the dialysis fiber, where it reached 8-12 mM. The $\left[\mathrm{K}^{+}\right]_{\circ}$ level was slightly higher in st. radiatum than in st. pyramidale, as illustrated in Figure 5 (double-headed arrow labeled 2), in which the $\mathrm{K}^{\prime}$ electrode was pushed deeper by $100 \mu \mathrm{m}$. The gradual accumulation of $\left[\mathrm{K}^{+}\right]_{o}$ between SD waves was paralleled by the depression of a-PS (compare Figs. $2,4 A, 5$ ). When SDs ceased and the a-PS was blocked, $\left[\mathrm{K}^{+}\right]_{\mathrm{o}}$ slowly declined (Fig. 5), most likely by clearing by the blood stream.

The negative shift of the DC potential was not an exact mirror image of the rise of $\left[\mathrm{K}^{+}\right]_{0}$. After the first SD wave, $V_{\mathrm{o}}$ remained at a strongly negative level and $\left[\mathrm{K}^{+}\right]_{0}$ recovered to nearly normal. Later, however, in the period between arrows 1 and 2 of Figure 5, the strong rise of $\left[\mathrm{K}^{+}\right]_{0}$ was more precisely correlated with an additional negative shift of $V_{\mathrm{o}}$.

After cardiac arrest induced by intracardiac injection of pentobarbital, two different patterns of terminal $\left[\mathrm{K}^{+}\right]_{0}$ increase were observed. In cases when the short probe was used and no SD waves had developed or the a-PS was not completely blocked, $\left[\mathrm{K}^{+}\right]_{\mathrm{o}}$ increased abruptly to $>30 \mathrm{~mm}$ accompanied by a sudden negative shift of $V_{\mathrm{o}}$, similar to that seen at the start of SD (Fig. $6 A$ ). By contrast, in cases when FC dialysis had induced recurrent SD waves and the a-PS had been suppressed, in the vicinity of the dialysis probe the $\mathrm{SD}$-like sudden onset $\Delta V_{\mathrm{o}}$ and $\Delta\left[\mathrm{K}^{+}\right]_{\mathrm{o}}$ were replaced by gradual, slow changes of $V_{\circ}$ and of $\left[\mathrm{K}^{+}\right]_{\circ}$ (Fig. $6 B, e l$ ). Yet in the same preparations at a location farther from the dialysis membrane, the more typical SD-like $\Delta V_{o}$ occurred (Fig. $6 B, e 2)$. The final $\left[\mathrm{K}^{+}\right]_{0}$ eventually reached levels between 40 and $70 \mathrm{~mm}$ in all cases (Fig. 6A,B).

\section{Diffusion and regulation of $\mathrm{K}^{+}$ions in the interstitial space}

'I 'he capacity of the tissue to control $\left[\mathrm{K}^{+}\right]_{0}$ was disrupted by $\mathrm{FC}$ treatment. As shown in Figure 5, perfusion of the dialysis probe of
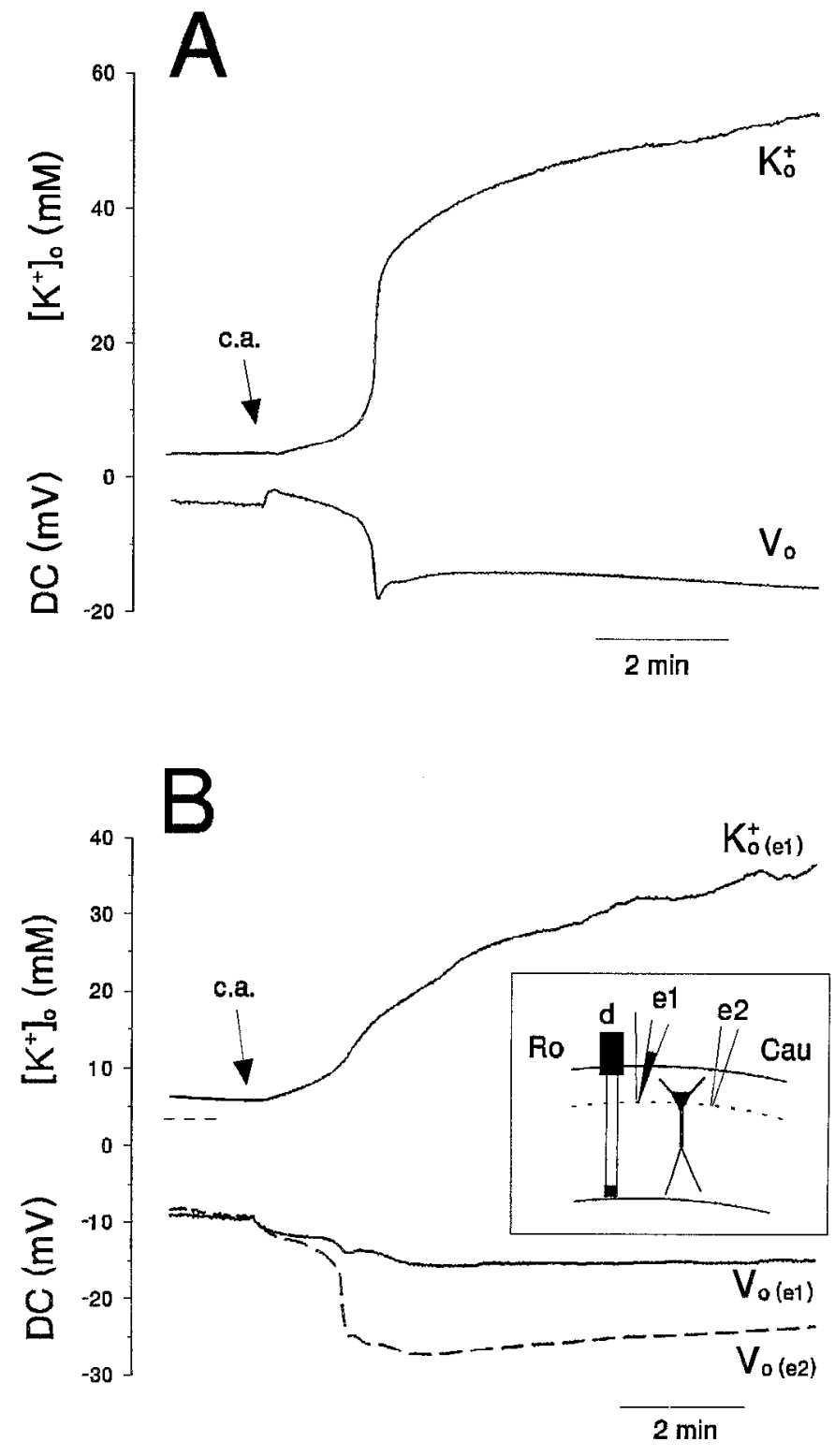

Figure 6. Interstitial $\mathrm{K}^{+}$and DC voltage during terminal ischemia after glia poisoning. $A$, Recorded in an experiment perfusing $\mathrm{FC}$ through a short dialysis probe. At the time of cardiac arrest (c.a.), the a-PS had been only partially blocked (as in Fig. $1 B$ ) and displayed the abrupt $\mathrm{K}^{+}$rise similar to control animals. $B$, From another animal in which $\mathrm{FC}$ was perfused through a long probe, and the a-PS was completely blocked at the time of killing. Note the reduced $V_{\mathrm{o}}$ deflection in the trace recorded near $\left[V_{o(e t)}\right]$, and the almost normal negative $V_{0}$ far from $\left[V_{o(e 2)}\right]$ the probe, indicating decreased neuronal damage away from the FC source at the dialysis fiber. The inset shows the arrangement of electrodes. Abbreviations are as in Figure $1 A$.

a solution containing $30 \mathrm{~mm} \mathrm{KCl}$ toward the end of the recording period after administration of $\mathrm{FC}$ caused a marked elevation of $\left[\mathrm{K}^{\prime}\right]_{0}$. By contrast, in normal hippocampus, perfusing a solution containing higher concentrations of $\mathrm{KCl}(100 \mathrm{mM})$ caused a minor increase of $\left[\mathrm{K}^{+}\right]_{0}$ only in the immediate vicinity of the dialysis membrane (Fig. 7A). Dialysis of high $\mathrm{K}^{+}$in agar gel detectably elevates $\left[\mathrm{K}^{+}\right]$as far away as $1 \mathrm{~mm}$ from the dialysis membrane (Fig. $7 A$ ). Using the same dialysis probe and solution in neocortex and in hippocampus, $\left[\mathrm{K}^{+}\right]_{o}$ remained at control level at $400 \mu \mathrm{m}$ from the probe; in hippocampus at $200 \mu \mathrm{m}$ from the probe it rose $<2 \mathrm{~mm}$, except when a wave of SD swept by the recording 

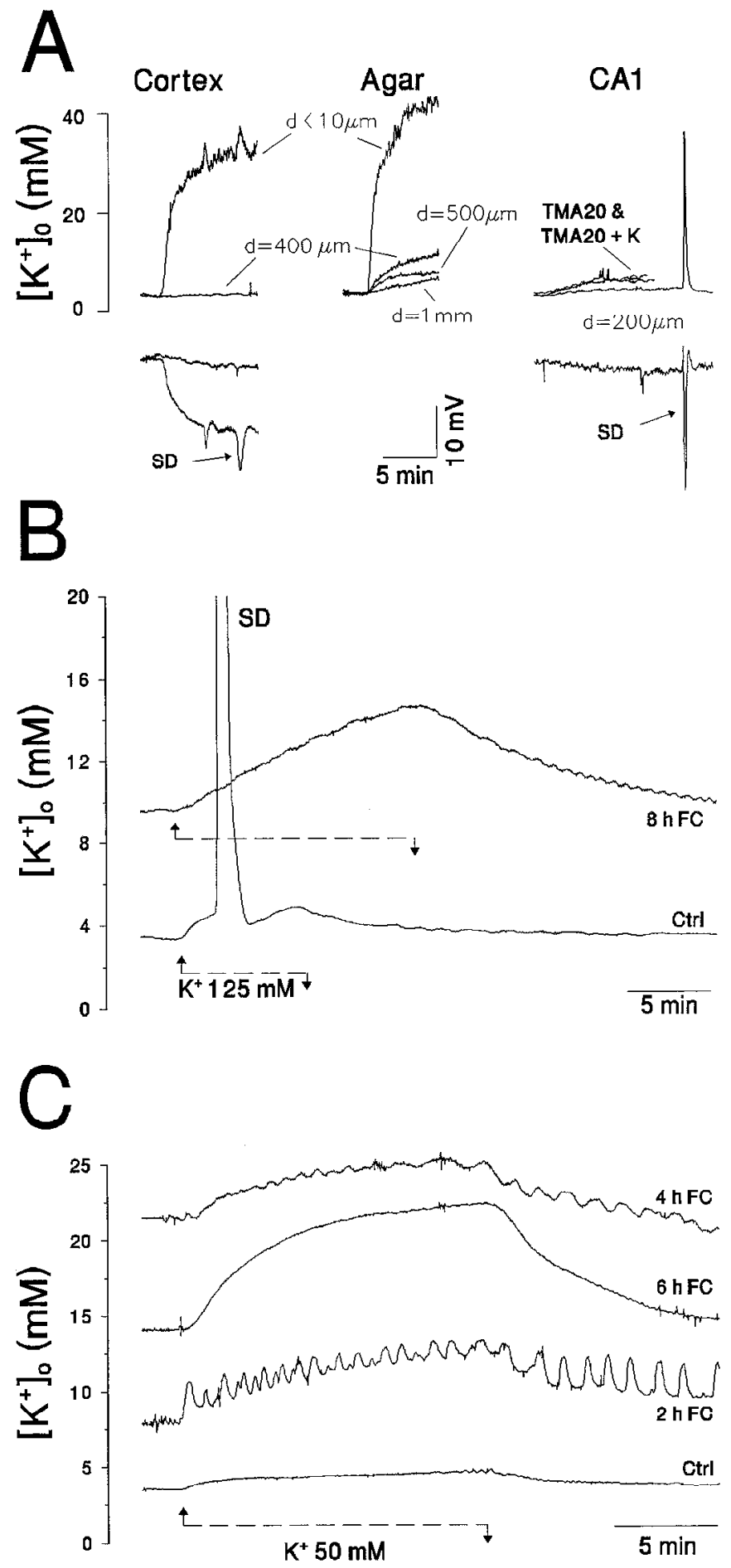

Figure \% Effect of glia poisoning on the diffusion of $\mathrm{K}^{+}$ions in the interstitium from an cxternal source (long dialysis probc). $A$, Control experiments. $\mathrm{KCl}$-modified $\mathrm{ACSF}(100 \mathrm{~mm})$ was perfused through the dialysis fiber and measured at different distances in neocortex, in Agar with $147 \mathrm{mM} \mathrm{NaCl}$ and $3 \mathrm{mM} \mathrm{KCl}$, and in $C A 1$. Superimposed on hippocampal trace are recordings during dialysis of $T M A$ and of $T M A+K C l$. At the same distance $(200 \mu \mathrm{m})$, TMA rose markedly, whereas $\mathrm{K}^{+}$was barely modified, evidence for the limited diffusion of the latter. $B$, From another experiment. Comparison of interstitial $\mathrm{K}^{+}$during dialysis of $125 \mathrm{mM} \mathrm{KCl}$ in control condition and after $8 \mathrm{hr}$ of $F C$, recorded in st. pyramidale $\sim 200$ $\mu \mathrm{m}$ from the dialysis fiber. The increased diffusion of $\mathrm{K}^{+}$is apparent. Note the shorter perfusion time in control $(C t r l)$. $C$, Similar experiment, but only $50 \mathrm{mM} \mathrm{KCl}$ dialyzed to avoid appearance of SD waves. Note different departure baseline levels of $\left[\mathrm{K}^{+}\right]_{0}$ at different times. a-PS was already completely blocked at $6 \mathrm{hr}$, but not yet at 2 or $4 \mathrm{hr}$.

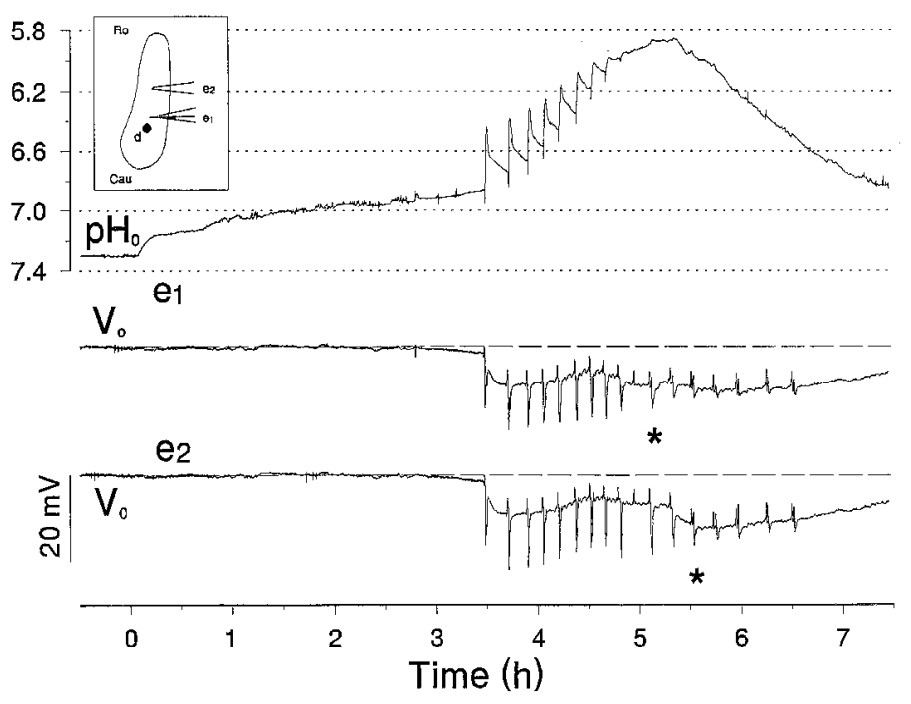

Figure 8. Interstitial $\mathrm{pH}$ during $\mathrm{FC}$ dialysis through a long probe. $\mathrm{FC}$ administration started at zero time. Asterisks in $V_{o}$ tracings mark the last $\mathrm{SD}$ wave able to invade the recorded position from its site of origin in neocortex; positive $V_{\text {o }}$ deflections after this time correspond to cortical SD waves. Electrodes $e 1$ and $e 2$ were located $200-300 \mu \mathrm{m}$ and $1 \mu \mathrm{m}$, respectively, from the dialysis fiber. Note the large acid envelope during SD waves; $R o$, rostral; $C a u$, caudal. Compare with Figure 5.

electrode (Fig. 7A). As a control experiment, when $20 \mathrm{~mm} \mathrm{TMA}^{+}$ was dialyzed, it did reach the recording electrode in the same location. Moreover, the combined dialysis of $\mathrm{TMA}^{+}$and $\mathrm{K}^{+}$ induced the same signal as did perfusion by $\mathrm{TMA}^{+}$alone (Fig. 7A).

To test the participation of glia and neurons in the clearance of exogenously added $\mathrm{K}^{+}$, we perfused varying concentrations (30$125 \mathrm{~mm} ; n=6$; see Materials and Methods) of $\mathrm{KCl}$ in different animals for $15 \mathrm{~min}$ at different times during $\mathrm{FC}$ treatment. In Figure $7 B$, the elevation of interstitial $\mathrm{K}^{+}$during $125 \mathrm{~mm} \mathrm{~K} \mathrm{~K}^{+}$ ACSF perfusion is shown before and $8 \mathrm{hr}$ after $\mathrm{FC}$ treatment. Before $\mathrm{FC}$ administration, the rise of $\left[\mathrm{K}^{+}\right]_{\mathrm{o}}$ was limited except for the transient peak caused by an episode of SD. After FC treatment, the baseline of $\left[\mathrm{K}^{+}\right]_{\mathrm{o}}$ was elevated even before $\mathrm{K}^{+}$dialysis; during perfusion of $\mathrm{KCl},\left[\mathrm{K}^{+}\right]_{\mathrm{o}}$ increased and continued to rise.

Figure $7 C$ illustrates an experiment in which only $50 \mathrm{~mm} \mathrm{KCl}$ was perfused to avoid inducing SD waves. After $2 \mathrm{hr}$ of FC treatment, baseline $\left[\mathrm{K}^{+}\right]_{\mathrm{o}}$ was already high, and dialysis of $50 \mathrm{mM}$ $\mathrm{K}^{+}$caused recurrent seizures accompanied by transient elevations of $\left[\mathrm{K}^{+}\right\rceil_{n}$. At $4 \mathrm{hr}$ of $\mathrm{FC}$ treatment, the baseline $\left[\mathrm{K}^{+}\right\rceil_{\curvearrowleft}$ was very high and $\mathrm{K}^{+}$dialysis caused a moderate additional increase of $\left[\mathrm{K}^{+}\right]_{\mathrm{o}}$. After $5 \mathrm{hr}$, when the a-PS was blocked, $\mathrm{K}^{+}$dialysis no longer induced seizures. At $6 \mathrm{hr}$ of treatment, the baseline $\left[\mathrm{K}^{+}\right]_{\mathrm{o}}$ was lower than at $4 \mathrm{hr}$ (compare Fig. 4), but now dialysis of $\mathrm{K}^{+}$ caused a greater increase, possibly augmented in part because of the steeper concentration gradient from probe to recording electrode (Fig. 7C). Oualitatively similar results were obtained in all six experiments.

\section{Changes in $\mathbf{p H}_{0}$}

In seven animals the $\mathrm{pH}_{\mathrm{o}}$ was monitored during $\mathrm{FC}$ perfusion through a long probe. Sonn after the start of FC treatment, $\mathrm{pH}_{\mathrm{o}}$ decreased gradually and progressively until the onset of SD waves (Fig. 8). Within 300-500 $\mu \mathrm{m}$ from the dialysis probe, $\mathrm{pH}_{\mathrm{o}}$ levels dropped $0.26 \pm 0.07 \mathrm{pH}$ units in a period of $3-4 \mathrm{hr}$. When the SD waves appeared, $\mathrm{H}^{+}$accumulated more steeply because of the 
protracted acid transients caused by each SD wave. A brief alkaline transient occurred at the onset of each SD wave (Kraig et al., 1983; Somjen, 1984) that gradually decreased. When the SD waves became extinct, $\mathrm{pH}_{\mathrm{o}}$ dropped back slowly to a level that was only slightly more acidic than it had been before the first SD. Similar to $\left[\mathrm{K}^{+}\right]_{0}, \mathrm{H}^{+}$ions showed a gradient away from the $\mathrm{FC}$ source. When the short dialysis probe was used and no SD waves appeared, only the gradual moderate acidification was observed $(n=3)$. $\mathrm{pH}$ also was measured in two of the experiments when SD waves were provoked by $\mathrm{K}^{+}$microinjection after only 2 hr of $\mathrm{FC}$ dialysis. In these trials, acid $\mathrm{pH}$ did not accumulate beyond the SD-related transients, indicating that some additional factor hinders recovery from SD-induced acidification in the later stage of FC poisoning.

\section{DISCUSSION}

Among the functions attributed to neuroglia, much attention has focused on the regulation of the levels of interstitial $\mathrm{K}^{+}$and $\mathrm{pH}$ (Walz and Hertz, 1983; Chesler, 1990; Kettenmann and Ransom, 1995). Although there is considerable indirect evidence supporting these ideas, the observations reported here are the first to indicate that disabling neuroglia indeed impairs the regulation of $\left[\mathrm{K}^{+}\right]_{\mathrm{o}}$ and $\mathrm{pH}_{\mathrm{o}}$.

The suspected importance of glial cells for the survival of neurons has been a subject of debate. Our data suggest that injury to neuroglia makes neurons vulnerable to repeated waves of depolarization that otherwise do not irreversibly damage. This observation could provide insight into the process by which neuron injury can spread after a focal ischemic insult from an infarcted brain region into the adjacent penumbral zone. Waves of SD emanating from the border of the infarcted area have been implicated in this process (cf. Hossmann, 1994), but repeated SD by itself does not cause neuron injury (Nedergaard and Hansen, 1988; Herreras and Somjen, 1993c). Impairment of glia in the penumbral region could aggravate the effect of the recurrent waves of SD.

\section{The time of disruption of glial function}

From data available in the literature, the actual status of glial cells after FC poisoning is difficult to determine. Suppression of ATP production has been demonstrated (Hassel et al., 1994), which leads to intracellular acidification, the accumulation of sodium, and cell swelling. Histology of our material confirmed the swelling of glial cells (Fig. 3). Yet others have reported that, in this condition, astrocytes are not killed because they appear restored $24 \mathrm{hr}$ later (Paulsen et al., 1987). However, it is generally believed that while they are under the influence of $\mathrm{FC}$, the function of glial cells is arrested. For example, rapid inhibition of stimulated cAMP (Stone et al., 1990) and a fast decline of ATP levels (Hasin et al., 1984) have been demonstrated.

For our purpose, it is necessary to determine when glial cells become inoperative. The lowering of extracellular levels of glutamine, which is synthesized exclusively by glial cells (MartínezHernández et al., 1977), has been considered a marker for glial function impairment (Quastel, 1978). Indeed, we also have found that glutamine began to decrease within $30 \mathrm{~min}$ of $\mathrm{FC}$ treatment and reached its lowest level in 2-3 hr (Fig. 4B). This vicw is also reinforced by the early and rapid increase of alanine (Fig. $4 B$ ) which, together with lactate, is an obligatory product of the anaerobic metabolism of glial cells derived from the excess of pyruvate unable to enter the halted TCA cycle. The fact that most of the alanine increment is attained within the first hour of FC suggests that anaerobic glycolysis also could be rapidly declining.

\section{Evidence for and mechanism and timing of neuron injury during protracted FC treatment}

Paulsen et al. (1987) noted that high doses of FC in vivo may be toxic not only for glia but also for neurons. In our experiments, injury to neurons was indeed evident in the histological specimens prepared after $8 \mathrm{hr}$ of FC dialysis. However, it is important to note that in histological specimens prepared after 4 hr of dialysis only glial cells appeared damaged; neurons were intact. Moreover, neuron damage occurred only when FC. was dialyzed through the long probe, even though glial cells were damaged severely also when the short probe was used. Within the hippocampal formation, neurons were equally exposed to $\mathrm{FC}$ administered through either of the two probes. The critical difference seems to be that administration by the long probe provoked recurrent SD waves, whereas administration by the short probe did not.

The timing of the deterioration of glia and of neurons revealed by histology is confirmed by the time course of both the depression of the a-PS and the changes in amino acid levels in the dialysate. After 4 hr of dialysis, a-PS decreased only slightly, but at the end of 8 hr a-PS could no longer be evoked. The levels of glutamate and taurine began to increase slightly soon after the start of FC administration. This could be caused by astrocyte swelling, which has been shown to cause the release of these compounds (Kimelberg et al., 1990b). The steep, simultaneous rise of glutamate, taurine, glycine, and GABA began, however, only after $4 \mathrm{hr}$ of $\mathrm{FC}$ treatment, which is very likely a consequence of the beginning breakdown of neuronal integrity.

It is important that neither the poisoning of glial cells nor recurrent SD provoked by means other than $\mathrm{FC}$ was sufficient to cause massive irreversible loss of neurons. Only when both glial loss and repeated SD were combined did they cause major neuron injury. Therefore, it seems that, normally, some aspect of glial metabolism protects neurons against irreversible injury by SD.

SD provoked in otherwise healthy, well oxygenated brain tissue also raises interstitial glutamate levels (Van Harreveld and Kooiman, 1965; Szerb, 1991; Fabricius et al., 1993) (O. Herreras, unpublished observations). The glutamate released by SD in normal brain, however, is cleared rapidly (Fabricius et al., 1993), probably by uptake by glial cells. The persistent rise of glutamate late during FC treatment is probably attributable to failure of glial uptake. Glutamate has been blamed for neuron injury in a variety of pathological conditions (Rothman and Olney, 1986), and it also may be a factor in the secondary neuron damage caused by FC. It need not be the only damaging influence, however, because lack of glial control allows increases in the concentrations of $\mathrm{H}^{+}, \mathrm{K}^{+}$, and possibly other as yet unidentified agents, which may mutually reinforce one another's actions.

We propose that the following sequence of events occurred in our experiments. Beginning after $30 \mathrm{~min}$ of $\mathrm{FC}$ administration, glial function was progressively impaired, causing glial swelling, tissue acidosis, and a moderate increase of $\left[\mathrm{K}^{+}\right]_{\circ}$. The gradually increasing acidosis and/or the shortage of transmitter glutamate could account for the depression of orthodromic transmission, whereas antidromic responses remained as yet preserved. The ultimate failure of all neuronal responses was related to the eruption of recurrent SD waves after 3-4 hr of FC administration. At this time glial cells were no longer functioning and, therefore, $\left[\mathrm{K}^{+}\right]_{o}, \mathrm{pH}_{\mathrm{o}}$, and glutamate did not recover between SD waves but reached intolerably high levels. We may speculate that in this state 
neurons became greatly swollen and that free cytosolic calcium rose and remained at toxic levels (Siesjö and Bengtsson, 1989; Jing et al., 1991). When the short probe was used, glial function and ion homeostasis were similarly altered, but the absence of SD waves greatly decelerated the damaging process.

It has been reported that repeated SD waves arise from the borders of cerebral infarcts and spread into the penumbra zone (Nedergaard and Astrup, 1986), where cell metabolism is compromised and glial cells are swollen. The repeated SD waves have been blamed for the neuronal death occurring in this region (for review, see Hossmann, 1994). This raises the possibility that FC treatment reproduces important aspects of cerebral infarction. Although in ischemic brain, neurons die before glia, the functioning of glial cells may be impaired at critical times for neuron survival. Glial swelling has been demonstrated in a variety of pathological brain processes. Astrocytic edema is the earliest pathological reaction to some cytotoxines and also has been demonstrated in brain infarct (Kimelberg et al., 1990a). The harmful effect of SDs thus could be limited to the penumbral surround of the infarct, as suggested by Hossmann (1994). We suggest that glial dysfunction is the critical factor common to $\mathrm{FC}$ poisoning and ischemic penumbra and that in the absence of glial protection neurons become vulnerable to repeated SD waves and, as a result, the necrotic zone expands and encroaches into the adjacent penumbra. Two different lines of evidence support this suggestion. Different treatments aiming to block either SD waves or astrocytic edema have been successful in decreasing brain damage in models of ischemia or concussion (Kimelberg et al., 1990a; lijima et al., 1992).

In our experiments, the reason that SD waves were induced by FC in ncocortex and not in hippocampus is not clear. Additional work focusing on changes in neocortex, therefore, is needed.

\section{The role of glia in the control of $\mathrm{K}^{+}$in interstitial fluid}

Astrocytes and perhaps oligodendrocytes are believed to participate in the clearing of excess $\mathrm{K}^{+}$from interstitial fluid by net uptake, by redistribution within the tissue, and by "siphoning" from brain tissue into capillary blood (Orkand et al., 1966; Gardner-Medwin, 1983; Walz and Hertz, 1983; Newman, 1986). During normal operation, $\left[\mathrm{K}^{+}\right]_{0}$ is believed to increase mainly because of release from neurons during activation. Neurons regain lost $\mathrm{K}^{+}$by the $\mathrm{Na}^{+}-\mathrm{K}^{+}$exchange pump. In the current experiments, $\left[\mathrm{K}^{+}\right]_{0}$ increased moderately before the eruption of SD waves. Because glial function was disrupted early and no consistent neuronal hyperactivity was observed, we infer that swelling-induced $\mathrm{K}^{+}$release from depolarized glia (Kimelberg and O'Connor, 1988) is the likely origin of this increase. This indicates that neurons are able to fairly control $\left[\mathrm{K}^{+}\right]_{\mathrm{o}}$ without aid by glia, albeit not perfectly. From our results it seems that, in the absence of glial assistance, neuronal transport keeps $\left[\mathrm{K}^{+}\right]_{0}$ at a steady but somewhat higher than normal level. We conclude that in the absence of SD or seizures, glia serve to fine-tune $\left[\mathrm{K}^{+}\right]_{\mathrm{o}}$ levels.

In the inilial state of $\mathrm{FC}$ poisoning, $\left[\mathrm{K}^{+}\right]_{\text {o }}$ remained nearly normal; however, when SD waves erupted there was a steep accumulation of interstitial $\mathrm{K}^{+}$. In healthy cerebral tissue, $\left[\mathrm{K}^{+}\right]_{\mathrm{o}}$ returns to normal levels between $\mathrm{SD}$ waves (Herreras and Somjen, 1993b) (this study). The accumulation of $\left[\mathrm{K}^{+}\right]_{0}$, between SD episodes was accompanied by a gradual reduction of the a-PS. This may be related to the failure of more and more neurons with each SD wave. Incapacitated neurons cannot recover the $\mathrm{K}^{+}$lost by $\mathrm{SD}$-related depolarization and, after membrane breakdown, will release additional $\mathrm{K}^{+}$to the ES. In turn, the greatly increased $\left[\mathrm{K}^{+}\right]_{0}$ causes the sustained depolarization of the surviving neurons, and this must contribute to their demise (Jing et al., 1991; Herreras and Somjen, 1993c). This interpretation is reinforced by the fact that FC-treated tissue that has undergone repeated SD waves and lost a-PSs did not show, after cardiac arrest, the SD-like terminal depolarization and abrupt increase of $\left[\mathrm{K}^{+}\right]_{\mathrm{o}}$ typical for ischemic brain (Hansen, 1985). SD-like hypoxic depolarization is related to an increase of neuronal membrane ion conductance (Phillips and Nicholson, 1979; Czéh et al., 1993) and could not occur if neurons had died previously. Presumably, dead cells have already released their $\mathrm{K}^{+}$content.

The slow terminal rise of $\left[\mathrm{K}^{+}\right]_{\mathrm{o}}$ after cardiac arrest in cases in which the a-PS had been blocked may be attributed to the diffusion of $\mathrm{K}^{+}$from distant, relatively undamaged regions, and to the efflux from glial cells.

Understanding the diffusion of $\mathrm{K}^{+}$ions in interstitial space is essential because of the universal participation of this ion in normal as well as in pathological processes (Lux and Neher, 1973; Gardner-Medwin, 1983; Nicholson and Rice, 1991). The very restricted increase of the concentration of $\mathrm{K}^{+}$in the face of very high concentration perfused in the dialysate demonstrates the high degree of efficiency with which the level of this ion is regulated in normal brain tissue (Fig. $7 A$ ). The contrasting increase of interstitial $\mathrm{K}^{+}$late during $\mathrm{FC}$ treatment underscores the role of glial cells in regulating $\mathrm{K}^{+}$levels. Although it is clear that both neurons and glia participate in the control of interstitial $\mathrm{K}^{+}$, their relative contribution cannot be accurately gauged because of the unknown degree and timing of changes in the heterogeneous interstitial volume fraction (McBain et al., 1990) and also because the timing of the demise of glial cells and of neurons can be estimated only approximately.

\section{$\mathrm{pH}_{\mathrm{o}}$ control}

The marked tissue acidosis during FC administration (Fig. 8) confirms the proposed role of glial cells in regulating $\mathrm{pH}_{\mathrm{o}}$. Glial cells are believed to contribute to $\mathrm{pH}$ regulation by the presence of carbonic anhydrase, especially in oligodendrocytes (Giacobini, 1962), and also through astrocytic membrane transport (Chesler and Kraig, 1989; Chesler, 1990). The origin of the excess of protons is difficult to determine because $\mathrm{pH}_{\mathrm{o}}$ is the joint function of several independent variables (Stewart, 1981; Kraig et al., 1983). Acid is generated in the normal course of metabolism, the chief sources being $\mathrm{CO}_{2}$ (acting through the Henderson-Hasselbalch reaction) and lactic acid. FC treatment promotes, at least initially, anaerobic glycolysis in glial cells, leading to lactate production. Extracellular acid transients during SD (Mutch and IIansen, 1984; Somjen, 1984) have been attributed to the increase of both $\mathrm{CO}_{2}$ and lactic acid (Mutch and Hansen, 1984; Kraig and Cooper, 1987). In the present experiments, repetitive SD waves provoked an additional cumulative acidosis (Fig. 8) in parallel with neuronal function decay and increased $\mathrm{K}^{+}$, which did not occur when SD waves were provoked early during FC treatment. Acid extrusion through voltage-dependent channels in depolarized neurons (Thomas and Meech, 1982) and glia (Chesler and Kraig, 1989) or membrane transport, and a late functional decay of oligodendrocytes during FC treatment (Paulsen et al., 1987) (this study), may account for this effect.

Besides failure of glia, we must also consider the possible role of local failure of the circulation for the impaired regulation of $\mathrm{pH}_{\mathrm{o}}$ during $\mathrm{FC}$ poisoning. Small vessels could be compressed when cells swell. The fact that $\mathrm{pH}_{\mathrm{o}}$ recovered partially after 
cessation of SD waves suggests, however, that blood vessels were not completely occluded, as can also be observed in Figure $4 B$. In this late phase of FC poisoning, the membrane function and buffer capacity of both neurons and glia probably were severely impaired, leaving only washout by blood to regulate $\mathrm{pH}$.

\section{Glial syncytium and long-distance effects?}

Surprisingly, histology revealed edematous glial cells at distances much farther from the dialysis probe than $\mathrm{FC}$ is expected to diffuse via the interstitium in a significant concentration. This observation reminds one of the quasi-syncytial properties of the glia network. Harmful metabolites could be transferred through gap junctions (e.g., lactate, $\mathrm{H}^{+}, \mathrm{Ca}^{2+}$, or $\mathrm{FC}$ itself), accelerating the decay of astrocytes located far from the dialysis probe. This may be correlated to the finding of small clusters of injured neurons scattered throughout the CA1 region in mildly damaged brain, suggesting some kind of long-distance impact on neuronal viability via glial syncytium and possibly by glia-to-neuron signal transfer (Nedergaard, 1994; Parpura et al., 1994).

\section{Glutamate metabolism, orthodromic transmission, and glia}

The rate of depression of orthodromic transmission was rather variable. In experiments in vitro reported by others, synaptic transmission in the CA1 region decreased during fluoroacetate treatment in 30 min (Keyser and Pellmar, 1994) or during FC treatment in 5-7 hr (Berg-Johnsen et al., 1993). The difference in timing may be because of the rate of uptake of the two compounds or technical differences in the preparation. It is important that orthodromic transmission consistently fails before the ability to generate action potentials, indicating that synaptic blockade is not attributable to a breakdown of electrogenic membrane function (Stone et al., 1990; Keyser and Pellmar, 1994).

Exhaustion of the supply of the neurotransmitter glutamate has been considered the cause of transmission failure (Keyser and Pellmar, 1994). The early decrease of the transmitter precursor glutamine is evident in our results and could be taken to support this view. Aside from glutamine produced by glia (Hamberger et al., 1979), neurons, however, can also use glucose as an alternative source for glutamate (Ward et al., 1983). This fact, together with the highly variable rate of the depression of orthodromic transmission, raises some doubt whether the lack of neurotransmitter is the main cause of synaptic failure during glial poisoning.

Alternatively, we consider two possible, not mutually exclusive, mechanisms for orthodromic transmission rundown. First, breakdown of perisynaptic glia may alter the physical structure of synaptic clefts, leading to a functional disengagement of pre- and postsynaptic elements, similar to the swelling and retraction of astroglial lamellae during prolonged neuronal activity (Wolf and Güldner, 1978). Second, tissue acidosis and increased $\mathrm{CO}_{2}$ levels are known to depress synaptic transmission (Balestrino and Somjen, 1988).

We propose that the selective poisoning of glia may serve as a valuable tool to study the role of these cells in cerebral function, particularly in glia-neuron interactions and in homeostasis.

\section{REFERENCES}

Balestrino M, Somjen GG (1988) Concentration of carbon dioxide, interstitial $\mathrm{pH}$ and synaptic transmission in hippocampal formation of the rat. J Physiol (Lond) 396:247-266.

Balestrino M, Aitken PG, Somjen GG (1989) Spreading depression-like hypoxic depolarization in $\mathrm{CA} 1$ and fascia dentata of hippocampal slices: relationship to selective vulnerability. Brain Res 497:102-107.
Berg-Johnsen I, Paulsen RF, Fonnum F, I angmoen IA (1993) Changes in evoked potentials and amino acid content during fluorocitrate action studied in rat hippocampal slices. Exp Brain Res 96:241-246.

Chesler M (1990) The regulation and modulation of $\mathrm{pH}$ in the nervous system. Prog Neurobiol 34:401-427.

Chesler M, Kraig RP (1989) Intracellular pH transients of mammalian astrocytes. J Neurosci 9:2011-2019.

Choi DW (1990) Cerebral hypoxia: some new approaches and unanswered questions. J Neurosci 10:2493-2501.

Clarke DD, Nicklas WJ, Berl S (1970) Tricarboxylic acid-cycle metabolism in brain: effect of fluoroacetate and fluorocitrate on the labelling of glutamate, aspartate, glutamine and $\gamma$-aminobutyrate. Biochem $\mathbf{J}$ 120:345-351.

Czéh G, Aitken PG, Somjen GG (1993) Membrane currents in CA1 hippocampal cells during spreading depression (SD) and SD-like hypoxic depolarization. Brain Res 632:195-208.

Fabricius M, Jensen LH, Lauritzen M (1993) Microdialysis of interstitial amino acids during spreading depression and anoxic depolarization in rat neocortex. Brain Res 612:61-69.

Gardner-Medwin AR (1983) Analysis of potassium dynamics in mammalian brain tissue. J Physiol (Lond) 335:393-426.

Giacobini E (1962) A cytochemical study of the localization of carbonic anhydrase in the nervous system. J Neurochem 9:169-177.

Hamberger A, Chiang GH, Nylén ES, Scheff SW, Cotman CW (1979) Glutamate as a CNS transmitter. I. Evaluation of glucose and glutamine as precursors for the synthesis of preferentially released glutaniate. Brain Res 168:513-530.

Hansen AJ (1985) Effects of anoxia on ion distribution in the brain. Physiol Rev 65:101-148.

Hasin Y, Doorey A, Barry WH (1984) Electrophysiological and mechanical effects of metabolic inhibition of high-energy phosphate production in cultured chick embryo ventricular cells. J Mol Cell Cardio 16:1009-1021.

Hassel B, Sonnewald U, Unsgard G, Fonnum F (1994) NMR spectroscopy of cultured astrocytes: effects of glutamine and the gliotoxin fluorocitrate. J Neurochem 62:2187-2194.

Herreras O (1990) Propagating dendritic action potential mediates synaptic transmission in CA1 pyramidal cells in situ. J Neurophysiol 64:1429-1441.

Herreras O, Somjen GG (1993a) Propagation of spreading depression among dendrites and somata of the same cell population. Brain Res 610:276-282.

Herreras O, Somjen GG (1993b) Analysis of potential shifts associated with recurrent spreading depression and prolonged unstable SD induccd by microdialysis of clevated $\mathrm{K}^{+}$in hippocampus of anesthetized rats. Brain Res 610:283-294.

Herreras O, Somjen GG (1993c) Effects of prolonged elevation of potassium on hippocampus of anesthetized rats. Brain Res 617:194-204.

Herreras O, Cuevas P, Largo C (1995) Is glia dysfunction the initial cause of neuronal death in ischemic penumbra? Paper presented at 4th International Workshop on Cerebrovascular Surgery, Chicago, IL, June.

Herreras O, Largo C., Ibarz JM, Somjen GG, Martín del Río R (1994) Role of neuronal synchronizing mechanisms in the propagation of spreading depression in the in vivo hippocampus. J Neurosci 14:7078-7098.

Herreras O, Menéndez N, Herranz AS, Solís JM, Martín del Río R (1989) Synaptic transmission at the Schaffer-CA1 synapse is blocked by 6,7-dinitro-quinoxaline-2,3-dione: an in vivo brain dialysis study in the rat. Neurosci Lett 99:119-124.

Hossmann KA (1994) Viability thresholds and the penumbra of focal ischemia. Ann Neurol 36:557-565.

Iijima T, Mies G, Hossmann KA (1992) Repeated negative DC deflections in rat cortex following middle cerebral artery occlusion are abolished by MK-801: effect on volume of ischemic injury. J Cereb Blood Flow Metab 12:727-733.

Jing J, Aitken PG, Somjen GG (1991) Lasting neuron depression induced by high potassium and its prevention by low calcium and NMDA receptor blockade. Brain Res 557:177-183.

Kettenmann H, Ransom BR (1995) Neuroglia. New York: Oxford UP.

Keyser DO, Pellmar TC (1994) Synaptic transmission in the hippocampus: critical role for glial cells. Glia 10:237-243.

Kimelberg HK, O'Connor EO (1988) Swelling of astrocytes causes membrane potential depolarization. Glia 1:219-224. 
Kimelberg HK, Barron KD, Bourke RS, Nelson LR, Cragoe EJ (1990a) Brain anti-cytoxic edema agents. Prog Clin Biol Res 361:363-385.

Kimelberg HK, Goderie SK, Higman S, Pang S, Waniewski RA (1990b) Swelling-induced release of glutamate, aspartate, and taurine from astrocyte cultures. J Neurosci 10:1583-1591.

Kraig RP, Cooper AJL (1987) Bicarbonate and ammonia changes in brain during spreading depression. Can J Physiol Pharmacol 65:1099-1104.

Kraig RP, Ferreira-Filho CR, Nicholson C (1983) Alkaline and acid transients in cerebellar microenvironment. J Neurophysiol 49:831-850.

Largo C, Cuevas P, Martín del Río R, Somjen GG, Herreras O (1995) Halting glia function in situ imitates neuron deterioration seen in penumbra of focal cerebral ischemia. Soc Neurosci Abstr 21:211.

Leão AAP (1944) Spreading depression of activity in the cerebral cortex. J Neurophysiol 7:359 390 .

Lerma J, Herranz AS, Herreras O, Abraira V, Martín del Río R (1986) In vivo determination of extracellular concentration of amino acids in the rat hippocampus: a method based on brain dialysis and computerized analysis. Brain Res 384:145-155.

Lodin Z, Booher J, Kasten FH (1970) Long-term cultivation of dissociated neurons from embryonic chick dorsal root ganglia in the Rose chamber. Exp Cell Res 59:291-298.

Lux HD, Neher E (1973) The equilibration time coursc of $\left[\mathrm{K}^{+}\right]_{\text {o }}$ in cat cortex. Exp Brain Res 17:190-205.

Martínez-Hernández A, Bell KP, Norenberg MD (1977) Glutamine synthetase: glial localization in brain. Science 195:1356-1358.

McBain CJ, Traynelis SF, Dingledine R (1990) Regional variation of extracellular space in the hippocampus. Science 249:674-679.

Mutch WАC, Hansen $\Lambda J$ (1984) Extracellular $\mathrm{pH}$ changes during spreading depression and ischemia: mechanisms of brain $\mathrm{pH}$ regulation. J Cereb Blood Flow Metab 4:17-27.

Nedergaard M (1994) Direct signaling from astrocytes to neurons in cultures of mammalian brain cells. Science 263:1768-1771.

Nedergaard M, Astrup J (1986) Infarct rim: effect of hyperglycemia on direct current potential and $\left[{ }^{14} \mathrm{C}\right] 2$-deoxy-glucose phosphorylation. $J$ Cereb Blood Flow Metab 6:607-615.

Nedergaard M, Hansen AJ (1988) Spreading depression is not associated with neuronal injury in the normal brain. Brain Res 449:395-398.

Newman EA (1986) High potassium conductance in astrocyte endfeet. Science 233:453-454.

Nicholson C, Rice ME (1991) Diffusion of ions and transmitters in the brain cell microenvironment. In: Volume transmission in the brain (Fuxe K, Agnati LF, eds), pp 279-294. New York: Raven.

Orkand RK, Nicholls JG, Kuffler SW (1966) Effect of nerve impulses on the membrane potential of glial cells in the central nervous system of amphibia. J Neurophysiol 29:788-806.

Parpura V, Basarsky TA, Liu F, Jeftinija K, Jeftinija S, Haydon PG (1994) Glutamate-mediated astrocyte-neuron signaling. Nature 369:744-747.

Paulsen RE, Contestabile A, Villani L, Fonnum F (1987) An in vivo model for studying function of brain tissue temporarily devoid of glial cell metabolism: the use of fluorocitrate. J Neurochem 48:1377-1385.
Phillips JM, Nicholson C (1979) Anion diffusion in spreading depression investigated with ion selective microelectrodes. Brain Res 173:567-571.

Quastel JH (1978) Cerebral glutamate-glutamine interrelations in vivo and in vitro. In: Dynamic properties of glia cells (Schoffeniels E, Frank G, Tower DB, Hertz L, eds), pp 153-162. Oxford: Pergamon.

Ramón y Cajal S (1992) Histología del sistema nervioso del hombre y de los vertebrados. Alicante: Vidal.

Rothman SM, Olney JW (1986) Glutamate and the pathophysiology of hypoxic/ischemic brain damage. Ann Neurol 19:105-111.

Siesjö BK, Bengtsson F (1989) Calcium fluxes, calcium antagonists and calcium-related pathology in brain ischemia, hypoglycemia and spreading depression: a unifying hypothesis. J Cercb Blood Flow Metab 9:127-140.

Somjen GG (1981) The why and the how of measuring the activity of ions in extracellular fluid of spinal cord and cerebral cortex. In: The application of ion-selective electrodes (Zeuthen T, ed), pp 175-194. Amsterdam: Elsevier.

Somjen GG (1984) Acidification of interstitial fluid in hippocampal formation by seizures and by spreading depression. Brain Res 311:186-188

Somjen GG (1988) Basic mechanisms in cerebral hypoxia and stroke. In: Mechanisms of cerebral hypoxia and stroke (Somjen GG, ed), pp 447-466, Ncw York: Plcnum.

Somjen GG, Aitken PG, Balestrino M, Herreras O, Kawasaki K (1990) Spreading depression-like depolarization and selective vulnerability of neurons: a brief review. Stroke 21:1/9-183.

Stewart P (1981) How to understand acid-base. New York: Elsevier.

Stone EA, Sessler FM, Weimin L (1990) Glial localization of adenylatecyclase-coupled $\beta$-adrenoceptors in rat forcbrain slices. Brain Res 530:295-300.

Szerb JC (1991) Glutamate release and spreading depression in the fascia dentata in response to microdialysis with high $\mathrm{K}^{+}$: role of glia. Brain Res 542:259-265.

Thomas RC, Meech RW (1982) Hydrogen ion currents and intracellular $\mathrm{pH}$ in depolarized voltage-clamped snail neurons. Nature 299:826 -828.

Van Harreveld A, Kooiman M (1965) Amino acid release from the cerebral cortex during spreading depression and asphyxiation. J Neurochem 12:431-439.

Vibulsreth S, Hefti F, Ginsberg MD, Dietrich WD, Busto R (1987) Astrocytes protect cultured neurons from degeneration induced by anoxia. Brain Res 422:303-311.

Walz W, Hertz L (1983) Functional interactions between neurons and astrocytes. II. Potassium homeostasis at the cellular level. Prog Neurobiol 20:133-183.

Ward HK, Thanki CM, Bradford HF (1983) Glutamine and glucose as precursors of transmitter amino acids: ex vivo studies. J Neurochem 40:855-860.

Wolf JR, Güldner F-H (1978) Perisynaptic astroglial reactions to neuronal activity. In: Dynamic properties of glial cells (Schoffeniels E, Franck G, Hertz L, Tower DB, eds), pp 115-118. Oxford: Pergamon. 